\title{
Details of Particulars of Benefit Finding through the Experiences of Breast Cancer Patients Analysis on Breast Cancer Journals Written by Patients
}

\author{
Migiwa Nakada1, Mizue Shiromaru ${ }^{1}$, Satomi Mizutani² \\ ${ }^{1}$ Department of Nursing, School of Health Sciences, Sapporo Medical University, Sapporo, Japan \\ ${ }^{2}$ Doctoral Course, Graduate School of Health Sciences, Sapporo Medical University, Sapporo, Japan \\ Email: mnakada@sapmed.ac.jp
}

How to cite this paper: Nakada, M., Shiromaru, M. and Mizutani, S. (2017) Details of Particulars of Benefit Finding through the Experiences of Breast Cancer Patients Analysis on Breast Cancer Journals Written by Patients. Open Journal of Nursing, 7 , 98-110.

http://dx.doi.org/10.4236/ojn.2017.71009

Received: November 22, 2016

Accepted: January 19, 2017

Published: January 22, 2017

Copyright $\odot 2017$ by authors and Scientific Research Publishing Inc. This work is licensed under the Creative Commons Attribution International License (CC BY 4.0).

http://creativecommons.org/licenses/by/4.0/

\begin{abstract}
This study aims to analyze the descriptions in breast cancer journals written by patients and to understand the experience of benefit finding among patients with breast cancer. We selected 22 such breast cancer journals written by patients published after 2000 in Japan. The extracted statements related to benefit finding of patients experiencing breast cancer from the 22 journals were subjected to a qualitative analysis, and the following seven benefit finding elements were extracted: "Gratitude toward others", "Benefits due to cancer", "Happiness at living a normal life", "Realization of and satisfaction with my growth", "Awareness of the meaning of my existence", "Hopes for life", and "Willingness to contribute to others". These benefit findings suggest that these particulars fulfill cultural, practical, spiritual, and social meanings, and lead to self-revaluation in daily life.
\end{abstract}

\section{Keywords}

Breast Cancer, Journals Written by Patients, Benefit Finding

\section{Introduction}

The incidence and mortality of breast cancer in Japan is increasing [1]. Patients with breast cancer live with an awareness of the "disease" for a long time because there is a risk of recurrence and metastasis of the cancer for ten years after surgery, the common initial treatment. For this reason, it has been anticipated that they will suffer from pain of various kinds and many studies have addressed physical and mental pain after surgery for breast cancer [2] [3] [4]. Further, 
Taylor [5] and Wand [6] have addressed the benefit finding (BF) that improves the will to live of patients with breast cancer. However, this topic is not well studied in Japan. Benefit finding encompasses the positive changes in attitudes brought about by the "experience of a disease", and is considered a cognitive response for patients to adjust to stressful circumstances [7]. We expect that an analysis of the conditions and the background where BF occurs, also among Japanese patients with breast cancer, will make it possible to identify ideas to assist in the support of patients so that they can lead a more comfortable life without deterioration in the quality of life during the long periods of life with the disease.

This study analyzes data obtained from "narratives by patients". Since 1998 when a study on Narrative Based Medicine by Greenhalgh and Hurwiz [8] attracted attention, research of "narratives by patients" has come to be regarded as an important method to promote patient-centered health care. Patients face the issues themselves by talking about their experience, and health care professionals show understanding of the patients and family by listening [9] and through this exchange the parties involved gain ideas to think about the clinical care. With this background, breast cancer journals written by patients (Journals) have been analyzed and utilized in research studies.

As concepts similar to BF, resilience, and post traumatic growth are also concepts known as adjustments to stress and trauma. In this study we perform an analysis using the concept of $\mathrm{BF}$ as the actual intensities and degrees of stress and trauma at surgery for breast cancer are not clear.

\section{Purpose}

This study aims to understand details of BF for patients with breast cancer experience arising from the "disease", and to gain ideas useful in the support of patients with breast cancer, based on the data from an analysis of descriptions in journals published in Japan.

\section{Methods}

\subsection{Definition of Terms}

Breast cancer journals written by patients (Journals): here defined as "private records where patients describe the process of struggling with a disease" as defined by Kadobayasi [10].

Benefit finding (BF): defined as personal positive changes brought about by the experience of breast cancer (and a cognitive response in adjusting to stressful circumstances).

\subsection{Research Period}

Data were collected from May to December, 2013.

\subsection{Literature Reviewed}

We searched books related to breast cancer in the Web database of "Paramedi- 
ca", a second-hand bookstore specializing in private volumes where patients describe the process of struggling with a disease, and identified 199 volumes. Of these 166 were available as of August 25, 2012, and excluding 61 volumes published before 2000, we reduced the number to 105 . Of the 105 we excluded 22 volumes that met the following exclusion criteria: 1) lack of cognitive and mental descriptions, 2) the author is not a patient, 3) the author is not Japanese, and 4) includes cases of other kinds of cancers. After examining the content of the remaining 83 volumes, we chose and analyzed 22 which were determined to have been written well enough to be analyzed. In Japan most laws related to dealing with cancer issues were established in the present form after the year 2000. Considering this background, in the paper we decided to focus on and analyze the books published in 2000 or later.

\subsection{Analysis}

Having read through the 22 volumes, we extracted statements that express positive changes brought about by the experience of breast cancer. After coding the statements and paying attention to similarities, we assigned categories and subcategories.

\subsection{Reliability and Validity}

Through discussion with co-researchers during the process of the analyses, we ensured reliability and validity.

\subsection{Ethical Considerations}

In using data of struggles with diseases published and openly available in such journals, we took care to handle the matters reported not to violate copyright, not to harm the persons and personalities appearing there, or bring dishonor to the authors.

\section{Results}

Table 1 details the 22 breast cancer journals written by patients (Journals). All the authors were women, aged 33 to 70 when the journals were published, and two were published after the authors had passed away. The duration of the struggle with the disease till the publication was from one year and seven months to 30 years. Extracting statements that were considered to be related to benefit finding (BF) from the 22 journals and performing a qualitative analysis, we extracted seven categories: "Gratitude toward others", "Benefits due to the cancer", "Happiness at living a normal life", "Realization of and satisfaction with my growth", "Awareness of the meaning of my existence", "Hope for life", and "Willingness to contribute to others". The results of this analysis are discussed in the following sections by category and are shown in Table 2. For notation style, double single marks (') are used for category names, angular brackets $(<>)$ for sub-categories, square brackets ([]) for code names, and italics (italics) for quotations from the narratives. 
Table 1. Overview of the journals.

\begin{tabular}{|c|c|c|c|}
\hline Author, Year & Occupation & Title & Publisher \\
\hline 1. Machiko MATSUI (2000) & sociologist & Living with Cancer in America & The Asahi Shimbun, Co. \\
\hline 2. Eiko UCHIDA (2001) & $\begin{array}{l}\text { patient advocacy } \\
\text { group leader }\end{array}$ & I hope to Pair Boobs & Hokusui* $^{*}$ \\
\hline 3. Michi NAKAJIMA (2003) & nonfiction writer & Fighting Cancer, Learning from Cancer, Living with Cancer & Bunshun Bunko* \\
\hline 4. Minori MIYATA (2003) & poet & Breast Cancer-Decision Making for My Life & Lyonsha* \\
\hline 5. Reiko TACHIKI (2004) & journalist & Boobs in Paris and Boobs in Japan & Shueisha, Inc. \\
\hline $\begin{array}{l}\text { 6. Mariko YAMAGUCHI } \\
\text { (2004) }\end{array}$ & housewife & $\begin{array}{l}\text { Why My Breast Cancer Was Overlooked What Can Be } \\
\text { Done by Me Who Have Half a Year to Live }\end{array}$ & The Asahi Shimbun, Co. \\
\hline 7. Setsuko TAHARA (2004) & ex-caster & Farewell Note-Breast Cancer Journal with Laughter & Shueisha, Inc. \\
\hline 8. Setsuko TAHARA (2004) & ex-caster & Give a Smile until One Last Breath & Kodansha, Ltd. \\
\hline $\begin{array}{l}\text { 9. Mikiko OTONASHI } \\
\text { Kunio MURAI (2004) }\end{array}$ & actress (husband) & $\begin{array}{l}\text { My Wife's Breasts } 16 \text { Years for Two of Us Who Lived with } \\
\text { "Breast Cancer" }\end{array}$ & Kobunsha, Co., Ltd. \\
\hline 10. Eri HIRAMASTU (2004) & singer & My Room, a Dress Shirt, And "My Truth" & Shueisha Inc. \\
\hline $\begin{array}{l}\text { 11. Kazuko HAMANAKA } \\
\text { (2004) }\end{array}$ & $\begin{array}{l}\text { patient advocacy } \\
\text { group leader }\end{array}$ & Holding a Hope in My Mind & Gariver Products, Co., Ltd. \\
\hline $\begin{array}{l}\text { 12. Michiyo YOKOUCHI } \\
(2005)\end{array}$ & singer, dancer & Letters to the Child from Mother with Cancer, Forever & Sony Magazines, Inc. \\
\hline 13. Takako WAT (2006) & $\begin{array}{l}\text { patient advocacy } \\
\text { group leader }\end{array}$ & Treasure Box of Love and Courage & Doyukan, Inc. \\
\hline 14. Tsuneko OGURA (2006) & doctor & $\begin{array}{l}\text { Wil-Before You Sleep, A Cassette Tape of Love Dedicated to } \\
\text { My Son from a Woman Doctor Who Got Cancer }\end{array}$ & Bookmansha $^{*}$ \\
\hline 15. Yuko EMON (2006) & actress & Emon Yuko's Diary of Cancer and Slow Life & The Asahi Shimbun, Co. \\
\hline 16. Atsuko MIYAZAKI (2006) & nurse & Dying As We live & Shinpusha* \\
\hline 17. Mayumi HONDA (2008) & journalist & I Can't Believe That a 34-Year-Old Person Gets Cancer & Evidence-sya Inc. \\
\hline 18. Rika YAMAUCHI (2008) & nurse & A Nurse Barely Living & Asukashinsha Publishing \\
\hline 19. Tsuneko OGURA (2009) & doctor & $\begin{array}{l}\text { Words from a Woman Doctor with Breast Cancer, A } \\
\text { Positive Prescription for Those Who Experience Relapse }\end{array}$ & Shufunotomo, Co., Ltd. \\
\hline 20. Makiko SATO (2010) & freelance writer & Living with Breast Cancer After Menopause & Chuokoron Shinsha, Inc. \\
\hline 21. Yoko SANO (2011) & $\begin{array}{l}\text { children's picture } \\
\text { book writer }\end{array}$ & I fully Intend to Die & Kobunsha, Co., Ltd. \\
\hline 22. Kaoru ANDO (2011) & doctor & When a Woman Doctor Gets Breast Cancer & $\begin{array}{l}\text { Metamor Publishing, Co., } \\
\text { LTD. }\end{array}$ \\
\hline
\end{tabular}

${ }^{*}$ As the publisher has no English name, we spelled the name based on the sound of Japanese letters.

\section{1. 'Gratitude toward Others'}

This category is generated from four sub-categories and describes situations related to overflowing feelings of gratitude and deepening relationships with closely related persons, family and patients with the same disease. The sub-category $<$ Happiness in deepened family ties $>$ includes codes identified by [I realized my family's kindness after developing cancer], which shows awareness of members of the family who accepted the patient, and [I noticed myself as needed by my family] which expresses that the experience of family relationships had deepened and that there were feelings of satisfaction with time spent with the family. $<$ Presence of a partner that became more important to me $>$ expresses an 
Table 2. Positive changes due to cancer experience.

\begin{tabular}{|c|c|c|}
\hline Category & Sub-category & Representative Code \\
\hline \multirow{10}{*}{$\begin{array}{l}\text { Gratitude } \\
\text { toward others }\end{array}$} & \multirow{3}{*}{ Happiness in deepened family ties } & I came to enjoy the time spent with my family. \\
\hline & & I felt gratitude to my family. \\
\hline & & I found I can relax best in the family. \\
\hline & \multirow{2}{*}{$\begin{array}{l}\text { Presence of a partner that } \\
\text { became more important to me }\end{array}$} & I noted another side of my partner's personality. \\
\hline & & I noticed that the load weighing me down has been lighter when I am with my husband. \\
\hline & \multirow{3}{*}{$\begin{array}{l}\text { Realization of and gratitude toward } \\
\text { people who accept me }\end{array}$} & I came to understand the feelings of others after developing cancer. \\
\hline & & I noticed there are people who listen to me after developing cancer. \\
\hline & & I noticed myself regenerated by consideration of others. \\
\hline & $\begin{array}{l}\text { Importance of words spoken } \\
\text { by those with the same } \\
\text { experience }\end{array}$ & I realized that words spoken by those with the same experience are encouraging. \\
\hline & $\begin{array}{l}\text { Activities to be engaged in after a } \\
\text { cancer diagnosis }\end{array}$ & I enjoy hobbies I prepared for in order not to be discouraged. \\
\hline \multirow[t]{2}{*}{$\begin{array}{l}\text { Benefits due to } \\
\text { the cancer }\end{array}$} & \multirow{2}{*}{ What I think was lucky } & $\begin{array}{l}\text { I decided to think that I was able to quit smoking as a reward for the amputation of the } \\
\text { breast(s). }\end{array}$ \\
\hline & & $\begin{array}{l}\text { I thought that I was lucky to have a right to sit in priority seats (in public transport) } \\
\text { thanks to the cancer. }\end{array}$ \\
\hline \multirow{4}{*}{$\begin{array}{l}\text { Happiness at } \\
\text { living a normal } \\
\quad \text { life }\end{array}$} & \multirow{2}{*}{$\begin{array}{l}\text { Pleasure in doing things that are } \\
\text { taken for granted }\end{array}$} & I was grateful that I could live to welcome the New Year. \\
\hline & & I appreciated that I could perform daily activities. \\
\hline & A feeling of peace recognized & I felt happy to do daily activities by myself. \\
\hline & through experiencing pain & I felt the joy of life without physical pain. \\
\hline \multirow[t]{2}{*}{$\begin{array}{l}\text { Realization of and } \\
\text { satisfaction with } \\
\text { my growth }\end{array}$} & $\begin{array}{l}\text { My growth achieved through the } \\
\text { cancer experience }\end{array}$ & $\begin{array}{l}\text { After the cancer experience, I became able to see a lot of things that had been invisible } \\
\text { before. } \\
\text { I learned the philosophy to be able to change something unfavorable to favorable. } \\
\text { I felt my own growth through experiencing cancer. }\end{array}$ \\
\hline & $\begin{array}{l}\text { Pleasure in re-recognizing my own } \\
\text { skills }\end{array}$ & I was pleased to recognize my skills. \\
\hline \multirow[t]{3}{*}{$\begin{array}{l}\text { Awareness of the } \\
\text { meaning of my } \\
\text { existence }\end{array}$} & $\begin{array}{l}\text { Awareness of the meaning of my } \\
\text { existence }\end{array}$ & $\begin{array}{l}\text { I became aware of my own existence after developing cancer. } \\
\text { I began to regard myself positively through experiencing cancer. }\end{array}$ \\
\hline & $\begin{array}{l}\text { Importance of life recognized } \\
\text { through experiencing cancer }\end{array}$ & $\begin{array}{l}\text { Thanks to cancer, I became able to notice what was impossible before. } \\
\text { I needed to face obstacles to learn about life. } \\
\text { I want to cherish my valuable experience of breast cancer. }\end{array}$ \\
\hline & $\begin{array}{l}\text { Willingness to make the most of } \\
\text { life }\end{array}$ & $\begin{array}{l}\text { What made me positive is holding on to life rather than acceptance of death. } \\
\text { Although we cannot change our innate fate, we can change destiny by ourselves. } \\
\text { I wish to treasure my limited time to the full. }\end{array}$ \\
\hline \multirow{5}{*}{ Hopes for life } & & I thought that I was given time to face my death. \\
\hline & $\begin{array}{l}\text { Time given by cancer to start life } \\
\text { again }\end{array}$ & $\begin{array}{l}\text { I learned to think the cancer was not entirely bad because I can prepare for it to the last } \\
\text { moment. }\end{array}$ \\
\hline & & I want to cherish every moment of my life while preparing for death. \\
\hline & $\begin{array}{l}\text { Appreciation for experiencing } \\
\text { cancer in the present age }\end{array}$ & I appreciate that I developed the cancer today when better treatment is available. \\
\hline & Awareness of living with cancer & The image of cancer has changed from death to living together. \\
\hline \multirow{3}{*}{$\begin{array}{l}\text { Willingness to } \\
\text { contribute to } \\
\text { others }\end{array}$} & $\begin{array}{l}\text { Cancer experience that impels me } \\
\text { to take advantage of }\end{array}$ & $\begin{array}{l}\text { I don't want anyone to experience breast cancer. } \\
\text { I wish to support others as much as I can. } \\
\text { I must have some mission because I am still alive although I was diagnosed as cancer. }\end{array}$ \\
\hline & $\begin{array}{l}\text { Improved understanding of the } \\
\text { attitudes of healthcare providers }\end{array}$ & I became able to understand patients' feelings. \\
\hline & toward patients & I reconfirmed my policy to extend a supporting hand to patients as a nurse. \\
\hline
\end{tabular}


awareness and sense of ease when the patient is in the company of the family, specifically the husband. The patient realized or discovered kindness and new aspects of the relationship with the husband, as shown by the statement that the person who follows me with the warmest heart is my husband, always staying with me. Patients tried to create time that was spent where husband and wife were alone, something which usually becomes possible after retirement, and they became aware of this as a fulfilling time for the couple. This category also includes the awareness that the existence of the husband eases the psychological burden on patients. < Realization of and gratitude toward people who accept me $>$ expresses the awareness that the patient feels supported by people other than family, and the patients realized they became more considerate of the feelings of others after developing cancer.

[Kind support from others is an unexpected gift arising from gratitude] expresses that patients were aware of feelings of gratitude towards consideration shown by others, and discovered that support from others have an effect on both parties (the patient and others). <Importance of words spoken by those with the same experience> expresses that the words help alleviate mutual feelings of distress which is possible only because both have experienced the same kind of cancer.

\section{2. 'Benefits Due to the Cancer'}

This category is generated from two sub-categories which describe the experience where patients felt "benefits" clearly in their daily life due to the disease, cancer. <Activities to be engaged in after a cancer diagnosis $>$ includes cases where hobbies patients had thought about for themselves, considering the present and future health conditions, now became enjoyable activities in daily life and not only for coping with cancer. <What I think was lucky $>$ includes situations such as that [I decided to think that I was able to quit smoking as a reward for the amputation of the breast(s)]. This code also represents the thought that this (the diagnosis) had a better effect than had been expected, implying "a bonus unexpectedly earned" (former ideas) and "an active effort to decide to regard something previously unfavorable as a reward" (latter).

\section{3. 'Happiness at Living a Normal Life'}

This category generated from the two sub-categories describes an awareness that patients recognize the value of things and matters in daily life that are taken for granted and which they had not noticed before developing cancer. <Pleasure in doing things that are taken for granted> expresses situations where patients feel happy to see annual events such as the new year and birthdays, recognizing that being able to be a part of all of such daily activities as a source of joy and happiness. $<$ A feeling of peace recognized through experiencing pain $>$ depicts situations where patients have noticed how happy and carefree life without physical pain was through experiencing the physical pain due to cancer, things they had taken for granted before experiencing cancer. 


\section{4. 'Realization of and Satisfaction with My Growth'}

This category is generated from two sub-categories describing situations where patients became aware that they had the ability to cope with cancer and overcome hardships. $<$ My growth achieved through the cancer experience $>$ describes situations where patients became aware that their perspective had changed through the experience of cancer, and realized that they themselves were able to develop despite the cancer and felt appreciation for the change. $<$ Pleasure in re-recognizing my own skills $>$ occurs when patients recognized that they themselves have developed skills after making efforts to cope with the distress due to cancer. As shown by the code [I would not have been able to make such efforts if I had not had this negative experience], patients recognized that pain and distress due to cancer had drawn out and helped develop their abilities.

\section{5. 'Awareness of the Meaning of My Existence'}

This category describes the positive awareness displayed by patients in relation to their existence. This awareness comes from many different experiences that the patients had, such as noticing something new and feeling happy. As this category is generated from one sub-category, we assigned the same name to both the category and the sub-category. The following statements represent this situation: I sometimes feel the meaning of my existence, thinking that suffering from cancer was not just a waste when I listened to the problems of someone else and the person thanked me, and I feel that I have come to appreciate myself more than before I developed cancer.

\section{6. 'Hopes for Life'}

This category is generated from five sub-categories and describes an awareness of the meaning of being alive and the thought that I have to make the best effort to the last minute. <Importance of life recognized through experiencing cancer> expresses situations where patients realized the significance of their life more deeply, knowing the profound meaning of life as described by [I realized the joy of living] even through the cancer that makes patients think about death and brings much distress. $<$ Willingness to make the most of life $>$ is the situations where patients try to concentrate energy on the time they are alive with an awareness that the time they have left is limited. <Time given by cancer to start life again> expresses the awareness that patients had second thoughts on how to live until the moment of death, and tried to complete their lives in a satisfactory manner, as described by [I want to cherish every moment of my life while preparing for death]. <Appreciation for experiencing cancer in the present age $>$ shows gratitude at being able to live positively with hope because the development of cancer treatment makes physical pain less severe than it used to be. $<$ Awareness of living with cancer $>$ shows that patients changed their ideas about cancer, regarding it as a partner to live together with rather than an enemy to fight. 


\section{7. 'Willingness to Contribute to Others'}

This category is generated from two sub-categories and describes the inclination that patients want to assist and contribute to the lives of others by making use of the cancer experience. <Cancer experience that impels me to take advantage of $>$ expresses the sense of mission of what the patients would like to or feel a need to (an urge to) make use of their experience of cancer to assist others who suffer from the same distress. <Improved understanding of the attitudes of healthcare providers toward patients $>$ expresses the decision of the authors of the report here who are healthcare providers to make use of their experience with cancer patients in providing care.

\section{Discussion}

Like the authors of the breast cancer journals written by patients (Journals) analyzed in this study, it can be inferred that many women who undergo amputation of the breast(s) are subject to severe psychological trauma as they notice their change in appearance and feel lost and imperfect as humans. The published journals may be an expression showing that the authors who experienced to live with the disease while facing and suffering from this condition desired to contribute a record of their experience to society. This section examines benefit finding (BF) as extracted from the journals by category, and finally provides a discussion of $\mathrm{BF}$.

\section{1. 'Gratitude toward Others'}

Examining the matters of the codes in Table 2, two types of awareness appear in relation to family, husband, and other close persons, and these can also be observed in all of the four sub-categories. One type is an awareness of the relationship patients had before developing cancer, and the patients became better aware of the meaning and value of the relationships after developing cancer. The other is the awareness of a strengthening of relationships and changes triggered by being diagnosed with cancer, and an awareness of new relationships with previously unknown people. Here, the relationships involve changes in or improvements of the quality. In either case, patients became aware of their own role in the relationship, and realized that they are supported by the relationships and appreciate the relationships.

After the amputation of the breast(s), changes in appearance as well as functional disorders occur, and patients are subject to these physical changes feeling that they have been deprived of a feminine trait. This experience may cause a crisis in or loss of self-image. In this case patients become aware that they are supported and needed by the family, and they come to feel they can be themselves in their family. These discoveries may remind them of the value that they have in themselves. It can be inferred that support by the husband makes them realize that they are wives and females even though they have had their breasts removed, giving them a secure and strong sense of safety and pleasure. Therefore, it is suggested that becoming aware of $<$ Other sides of the partner's perso- 
nality $>$ is a discovery in the relationship of the couple, and the relationship becomes deeper and stronger. The pleasure obtained when patients realize that they have remained the same and are still playing their roles in the family, and that their ways are not inferior to what it was before losing their breast(s) would be a significant factor to improve their resilience as patients with breast cancer. Although there is a similar awareness in the relations to friends and close persons other than family, patients experience new facets in relationships. It can be inferred that they may have many opportunities to feel thankful for support provided by the people surrounding them in writing and publishing the breast cancer journals.

People who have experienced breast cancer confirm and revaluate themselves in terms of triple-structured relationships with husband, family, and other close persons. They may reconstruct their identity, something which has nearly entirely been taken away from them, in the three kinds of relationships after experiencing the disease, cancer, and surgery, having maybe felt as if their identity had been lost. We think that this pleasure and appreciation as regaining an identity once almost lost is the central concept of this category.

\section{2. 'Benefits Due to the Cancer'}

The sub-category, $<$ What I think was lucky $>$ includes humorous expressions such as regarding the success in quitting smoking as a "reward" for the amputation of the breast(s), and a comment such as that [I thought that I was lucky to have a right to sit in priority seats (in public transport) thanks to the cancer]. These expressions could show the intention the authors try to think of their hardships as $\mathrm{BF}$ through different perspectives as well as by their own trying to do the best to survive.

Humor is defined as something people need by nature, and something they cannot live without [11]. Frankl has stated that "It is well known that humour, more than anything else in the human make-up, can afford an aloofness and an ability to rise above any situation, even if only for a few seconds" ([12], p. 35). We think humor can create an "objectivity" to look out over all of life and ourselves even in serious situations. It is not clear whether the authors developed the scope to become objective while writing the journals or the objective perspective was acquired through the help of humor in fighting against cancer. However, assuming that people who experienced breast cancer have a sense of humor would be a key to understand their psychological condition. Johnson analyzed the narratives of women with breast cancer and reported that humor is a significant coping strategy [13]. This leads us to believe that humor is a viewpoint that deserves more attention in the development of nursing sciences.

\section{3. 'Happiness at Living a Normal Life'}

The sub-category, $<$ Pleasure in doing things that are taken for granted $>$ includes cultural, practical, and spiritual aspects rooted in Japanese traditional life-styles, such as "welcoming the new year", where patients appreciate the day-to-day 
routines they have lived with before developing cancer. Culture is defined as sense of value and belief that is learned and passed down [14], and people have lived in the culture by learning many things since we were born. Culture links the individual person and society firmly. The experience to notice that we can be in the same culture as before seems to help us confirm our feeling of comfort, leading to a sense of relief and convincing each of us that even now I am good enough really. Therefore, "what is taken for granted" can be assumed to be an extremely valuable awareness for people experiencing breast cancer.

\section{4. 'Realization of and Satisfaction with My Growth'}

This category describes how patients realize that they have developed based on the cancer experience and how strong they have become overcoming the distress of cancer. As the codes in Table 2, patients became aware that they developed as persons because they have overcome the hardships of cancer, and have even shown appreciation for the cancer experience.

Post Traumatic Growth (PTG) is defined as the "experience of development as a person growing out of pain and mental struggles due to a very adverse condition" [15]. 'Realization of and satisfaction with my growth', one BF identified by the analysis in this study is the awareness that patients were able to develop themselves by their own ability to overcome the distress of or by overcoming the hardships of cancer. This is very similar to PTG, and we will examine the correlation between PTG and BF that results in benefits in future studies.

\section{5. 'Awareness of the Meaning of My Existence'}

The statement that I sometimes feel the meaning of my existence, thinking that suffering from cancer was not just a waste when I listened to the problems of someone else and the person thanked me implies that patients questioned themselves about the reason for their existence after developing cancer. It is natural that experience of a sense of loss due to the disease and surgery makes a gap between the ideal self before experiencing cancer and actual self now, and there will be gaps and shifts in self-cognition. Endo suggests that such gaps will bring individuals into emotional conflict [16]. Many people who experience breast cancer may suffer different kinds of conflict. However, realizing that they are of help to others and understanding that their experience will be empowering is important for them to reconsider themselves positively and reconstruct an ideal self.

\section{6. 'Hopes for Life'}

The four sub-categories that generated this category depict process from where patients became aware of death till they determined how they wished to live till death intrudes. All the codes extracted in this study describe situations where patients question themselves as to what they can do and how they want to live to the very last moment considering the time left, facing these obstacles in conjunction with the awareness of cancer, and in the unavoidable fear of death. We in- 
terpret 'Hopes for life' as BF to strive towards self-realization, powerfully after suffering anguish with fear of death. This BF may be unique in that it is generated when patients are forced to realize that they suffer from a disease that it is difficult to be cured from like a cancer is and that there is only a limited time left before death.

\section{7. 'Willingness to Contribute to Others'}

This category can be interpreted as a BF that comes from awareness of social roles which patients can play only because they have experienced breast cancer or because it is a mission the patients feel a need to do. $<$ Discovery of the significance of words of a person who has had a similar experience> included in 'Gratitude toward others' expresses that advice and words from persons who have experienced the same affliction with breast cancer was valuable. In case of a 'Willingness to contribute to others', it seems that patients who experienced breast cancer desire to use their experience to help others, contributing their experience to persons who are at a loss with the disease like they themselves used to be. It can also be interpreted as a genuine desire to help others to avoid suffering from the hardships they went through.

A study of BF among patients with collagen diseases in Japan has reported a characteristic that was expressed as "I was getting to desire to help others" [7], and a study of BF among patients with psychiatric disorders has identified a desire to help others, reporting "finding a new role in society" [17]. 'Willingness to contribute to others' can be a BF unique to the Japanese who experience diseases, because it has not been reported as a BF in studies from outside Japan as the two studies cited above pointed out. However, it is not probable that an awareness of contributing to others has not occurred because volunteer activities are actively conducted in Western culture. Future studies need to explore this difference comparing cultural areas.

As described above, this study examined each category separately, and found that the authors of the journals felt appreciation for "common practices", "living", and "others" and had hopes to make the most of life again, while pondering on themselves and the discontinuity in their lives. The findings also suggest that patients revaluate themselves and find meaning in their existence while developing an appreciation of others. Pain and distress due to diseases generate irregularities in daily lives and routines. Therefore, we think that patients are motivated by trying to find meaning in the adverse event, trying to understand the event intentionally, and alter their world view, and eventually BF is the result. This study cannot determine the process of trying to find meaning in the surveyed journals, because we focus on BF identified as a result of analysis. However, as patients who recognize BF due to diseases do revaluate and reconstruct themselves, it can be inferred that they improve in resilience by positively making efforts to find meaning in their experience.

Journals were written by authors who "wished to write", and included statements that express the desires of the authors, including the helping of others by 
publishing their personal experience of breast cancer or by contributing their experience to the wider society. For this reason, extracting BF may have been relatively easy in this study. However, we believe that positive changes through the experience of cancer do occur. As a study has reported that patients will be better adapted to life with cancer five to eight years later if they achieve BF in the year they were diagnosed with breast cancer [18], it is necessary for healthcare providers to pay attention to BF at the early stages of the diagnosis. The present study does not clearly establish whether all patients with breast cancer experience positive changes in their lives. To understand the various and complicated total pain experienced by breast cancer patients is important and meaningful and we, nurses, should not interact with patients on the assumption that they will obtain BF. However, breast cancer patients have the potential to survive while struggling with the disease by obtaining BF under specific conditions. We are well aware that it is necessary to examine these conditions in future studies, and believe that $\mathrm{BF}$ due to a disease is a worthwhile subject that needs to be addressed further as a key element for patients with cancer thinking about how to survive.

\section{Conclusion}

This study analyzed the contents of 22 breast cancer journals written by patients focusing on positive changes, and seven categories were identified. The findings suggest that these seven positive changes were self-revaluation made in the process of living after the patients underwent surgery, by trying to find the meanings of each event in daily life while relating the occurrences to the social context or the context of illness trajectory.

\section{Acknowledgements}

We wish to thank Mr. Takehiko ITO, Ms. Michiko KADOBAYASHI, and Ms. Mikiyo SATO for their cooperation in the analyses. We are deeply grateful to authors of breast cancer journals for valuable messages. This work was supported by MEXT/JSPS KAKENHI (Grant-in-Aid for Scientific Research (C), No. 24593307).

\section{References}

[1] Japanese Breast Cancer Society (2015) Breast Cancer Clinical Practice Guideline Based on Scientific Evidence, 2. Epidemiology and Diagnosis. Kanehara \& Co., LTD., Tokyo, 2-5.

[2] Senoo, M. (2009) Hope and Anxiety of Patients with Breast Cancer: Effects of Support from Families, Peer Patients and Significant Others. Japanese Journal of Maternal Health, 50, 334-342.

[3] Sunaga, M. and Futawatari, T. (2013) Current Status and Future Perspectives of Nursing Support Strategies within Cancer Survivorships in Breast Cancer Survivors in the Extended Stage of Survival. The Kitakanto Medical Journal, 63, 345-355. https://doi.org/10.2974/kmj.63.345

[4] Wang, A.W., Chang, C.S., Chen, S.T., Chen, D.R. and Hsu, W.Y. (2014) Identifica- 
tion of Posttraumatic Growth Trajectories in The First Year after Breast Cancer Surgery. Psycho-Oncology, 23, 1399-1405. https://doi.org/10.1002/pon.3577

[5] Tayler, E.J. (2000) Transformation of Tragedy among Women Surviving Breast Cancer. Oncology Nursing Forum, 27, 781-788.

[6] Wang, Y., Zhu, X., Yang, Y., Yi, J., Tang, L., et al. (2015) What Factors Are Predictive of Benefit Finding in Women Treated for Non-Metastatic Breast Cancer? A Prospective Study. Psycho Oncology, 24, 533-539. https://doi.org/10.1002/pon.3685

[7] Sato, M. (2007) Characteristics of Benefit-Finding and Factors Related to Its Formation among People with Collagen Disease. Journal of Comprehensive Nursing Research, 10, 15-25.

[8] Greenhalgh, T. and Hurwitz, B. (1998) Narrative Based Medicine. Dialogue and Discourse in Clinical Practice. BMJ Books.

[9] Charon, R. (2006) Narrative Medicine: Honoring the Stories of Illness. Oxford University Press, New York, vii.

[10] Kadobayasi, M. (2011) Sociology with Cancer Patient Narratives, for the Source of Power to Live. Seikaisha Co., Ltd., Tokyo, 1-15.

[11] Kashiwagi, T. (2007) Power to Live. Journal of Comprehensive Nursing Research, 9, 1-14.

[12] Frankl, V.E. and Winslade, W.J. (Afterword) (2006) Man's Search for Meaning. Beacon Press, Boston, 35.

[13] Johnson, P. (2002) The Use of Humor and Its Influences on Spirituality and Coping in Breast Cancer Survivors. Oncology Nursing Forum, 29, 691-695. https://doi.org/10.1188/02.ONF.691-695

[14] Leininger, M.M. (1992) Culture Care Diversity \& University. A Theory of Nursing. National League for Nursing, Inc., New York.

[15] Taku, K. (2014) Triggers of PTG, When People Develop from Sorrow-PTG. Kazamashobo, Tokyo, 52.

[16] Endo, T. (1998) The Psychology of Identity. Nakanishiya Shuppan, Tokyo, 92-94.

[17] Chiba, R., Miyamoto, Y. and Funakoshi, A. (2010) Characteristics of Benefit-Finding in People with Mental Illness. Journal of Japan Academy of Nursing Science, 30, 32-40. https://doi.org/10.5630/jans.30.3_32

[18] Carver, C.S. and Antoni Michael, H. (2004) Finding Benefit in Breast Cancer during the Year after Diagnosis Predicts Better Adjustment 5 to 8 Years after Diagnosis. Health Psychology, 23, 595-598. https://doi.org/10.1037/0278-6133.23.6.595 
Submit or recommend next manuscript to SCIRP and we will provide best service for you:

Accepting pre-submission inquiries through Email, Facebook, LinkedIn, Twitter, etc. A wide selection of journals (inclusive of 9 subjects, more than 200 journals)

Providing 24-hour high-quality service

User-friendly online submission system

Fair and swift peer-review system

Efficient typesetting and proofreading procedure

Display of the result of downloads and visits, as well as the number of cited articles Maximum dissemination of your research work

Submit your manuscript at: http://papersubmission.scirp.org/

Or contact ojn@scirp.org 